\title{
Capability of the Russian women in science: support required
}

\author{
Aleksandr Mikhailovich Egorychev ${ }^{1}$, Anna Gogievna Akhtyan ${ }^{{ }^{*}}$, Irina Aleksandrovna \\ Fedoseeva $^{2}$, Svetlana Nikolaevna Fomina ${ }^{1}$, and Aleksandr Maksimovich Tyutchenko ${ }^{3}$ \\ ${ }^{1}$ Russian State Social University, Social Work Department, Moscow, Russia \\ ${ }^{2}$ Novosibirsk State Pedagogical University, Department of Practical and Special Psychology, \\ Novosibirsk, Russia \\ ${ }^{3}$ Moscow City Pedagogical University, Department of Special Psychology and Psychosocial \\ Technologies, Moscow, Russia
}

\begin{abstract}
The article considers the problems related to the development of the capability of Russian women in science, necessity to optimize the scientific capability of the students of a higher educational institution. The objective of the research: a scientific grounding of the focused support of the woman's scientific capability in Russia and the development of the perspective directions of its optimization. The methods of information collection: theoretical (analysis, synthesis, comparison, correlation and generalization of the author approaches in the scientific literature) and empiric (observation, conversation, interview, sociological poll) regarding the state and perspectives of the development of the scientific capability of the Russian women. The conditions and reasons were revealed that do not allow realizing the capability of the Russian women in science completely; the conditions of optimization of the development of the scientific capability of the students of a higher educational institution were discovered taking into account the gender aspect; the conclusions were obtained that are related to the optimization of the woman capability in the scientific activity in all the fields of the country. The novelty of the research performed is the following: the historical and social role of a woman in science and education was shown, the necessity of development of the woman scientific capability in the country was grounded; the fields of scientific interests of the students of a higher educational institution were revealed and grounded taking into account the gender aspect; the possibilities for optimization of the scientific capability of the students were determined.
\end{abstract}

Keywords: woman scientific capability, vocational education system, gender aspect, Russian women

\section{Introduction}

\footnotetext{
* Corresponding author: ahtvananna@mail.ru
} 
The present problem is urgent not only for Russia; it is typical for all countries in the world. Thus Khamdamova believes that "... there is lack of women-scientists is still observed in the world as well as the absence of women-researchers and scientists taking the high managerial positions" [1].

This problematics attracts national researchers: Russian women-scientists: historical aspect [2]; gender aspects in science and education [3, 4]; women in science and education [4-9]; student science: gender aspects [10, 11], self-development of women [12].

This problem attracts also the attention of the foreign authors [13-20].

Analysis of the scientific literature allows discovering the availability of certain nuances in the present problem:

- There is an interest in the gender problem and a woman role in the development of society all over the world;

- Solution of the problem of woman's capability support in science relates to the activity of the entire Russian educational system taking into account the gender approach.

Thus Enloe in his article "Gender Makes the World Go Round" discusses in detail and thoroughly the problems of the world's existence within the frameworks of the gender approach [15].

In their research Holman, Stuart-Fox and Hauser raise a clear question: how much time will it take before the women are equally represented in science? [19].

Burdukovskaya and Rvacheva notice: "The introduction of the category "gender" into the pedagogical process has a principal significance as in the higher educational institution many ideas of the professional identity are formed as well as of the life strategy, access to the resources and power based upon the socio-gender orientation" [21].

The history of Russia has many witnesses that show the significant contribution of women to the development of their Motherland. Let us take as an example those women scientists who contributed significantly to the development of Russian science (Romanskaya, Kovalevskaya, Sklodowska-Curie, Karavaeva, Zeigarnik, Oleinik, etc.). Even in the $18^{\text {th }}$ century, Russian women were actively involved in scientific and educational activities. Ekaterina II supported the woman education in the country. Valkova notices: "Her Majesty and the high society following her looked quite favorably at the exercises of women in the sciences" [2].

The present tendency was supported in Russia after the 1917 October Revolution. The Council of People's Commissars of RSFSR prepared and issued a DECREE dated on August 02, 1918 "Of the rules of admittance into the higher educational institutions" that clearly stated: "Every person regardless his citizenship and gender who has reached the age of 16 years can join the listeners of any higher educational institution without producing the diploma, certificate of secondary education or any school-leaving certificate".

Pushkareva writes: "If until 1917 only 10\% of Russian women had access to the scientific work, for a short period of fifty years a number of women-scientists grew 5 times in our country. ... The process of feminization of science in our country in comparison with Europe and the USA was always progressive and was not limited, and on the contrary, it was encouraged all the time" [7].

Due to the positive historical processes by the beginning of the $21^{\text {st }}$ century, a share of Russian women studying in the system of higher education was akin to the men and exceeded them. Thus according to the data of the All-Russia census 2010 (collected volume of Russian Federal State Statistics Service (Rosstat) "Men and women of Russia") - 58\% women have higher education (15975 thousand people) and 42\% men (11556 thousand people). Meanwhile, a number of women engaged in the scientific fields was significantly lower in comparison with men. In Russia according to the data of Rosstat 136.4 thousands 
of women-researchers work in the field of research and development, which is 39.2 of the total number of researchers [22].

Nevertheless, in Russian science there is a bigger number of women in comparison with other countries - about 50\%; in Japan, they are $16 \%$, in Great Britain - 23\%, in Germany $20 \%$, in the USA $-36 \%$, in France $-28 \%$ [6]. If in 1991 a number of women in science was $51 \%$, by 2000 it was $63 \%$ of the total number of scientific researchers [5].

There are so-called "dark sports" regarding the carrier growth of a woman in science. Women are weakly represented in the management bodies of science and higher educational institutions of the country, they rarely are at the head of the large research groups, there are only $19 \%$ women among the heads of the laboratories, and among the deputy directors $-4 \%$, and among the heads $-2 \%[7]$.

\section{$2 \quad$ Materials and methods}

Objective of the research: the grounding of the necessity to support the capability of the Russian women in science and development of the perspective directions of its optimization. Tasks: the grounding of the necessity to develop the women's scientific capability in the country; revealing of the sphere of scientific interests of the students of higher education institutions taking into account the gender component. Research methods: theoretical and empirical. Research tools included: a questionnaire (12 questions) for polling of the students of the Russian State Social University - 14 faculties. Sampling procedure: age of interviewed students is 18-25 years; sampling population: \pm 894 respondents, including 484 - girls, 410 - young men. Time of research: 04.04.-21.12.2020.

\section{$3 \quad$ Results}

\subsection{Theoretical analysis of the research problem}

The reasons were revealed that do not allow to implement the capability of the Russian women in science completely:

- The standard historical socio-cultural tradition related to the positive attitude to the male status and its activity in the affairs of state and society, belittling of the woman status, giving her the secondary roles in all social spheres.

- The main concept of the woman's scientific capability is a socio-humanistic sphere and to a lesser extent - physico-mathematical, natural scientific, technical directions. The reason is the stereotype established in the Russian consciousness- a woman has a quite different set of mind that does not correspond to the exact sciences.

- Absence of enough time for women as it is required by the scientific type of activity, their involvement in the problems of creation, maintenance and preservation of the family (household worries, birth of children, their upbringing, etc.).

- Absence of proper upbringing in the higher education system regarding the working out of the sustainable motivation of the students to the scientific activity taking into account the gender component. 


\subsection{Empiric analysis of the research problem}

The information was collected that characterized the students' scientific capability at a higher educational institution taking into account the gender aspect. We shall represent the results obtained on a selective basis and comment them in brief.

Question: What do you think, does the educational process at the university promote the formation of researcher skills among the students?

A half of all respondents $(54.8 \%)$ believe that the educational process at the university promotes the formation of researcher skills among students; $19.2 \%$ do not agree; $26.0 \%$ have no answer. The distribution of the responses of the young men and girls does not have many deviations according to the gender, they are equal.

Question: How do you estimate the level of your involvement in the research work of the university?

The estimation was not at the high level: only $0.8 \%$ of the respondents estimated it as "quite high"; $13.9 \%$ estimated it as "high"; one third (37.7\%) estimated their participation at the "medium" level; $19 \%$ estimated it at the "low" level; $13.9 \%$ - at the "very low" level; $11.7 \%$ had no answer.

Question: What could increase your motivation for the research activity?

The students evaluated rather critically their mechanisms of development of motivation to active participation in the research work. Surprisingly one-third of students (31.3\%) was undecided. The "introduction of the material reward" was rated first (26\%); and the "active and accessible organization of research work on the Chairs of the faculty" was rated second $(16.2 \%)$; the "improvement of the informational and material support of the research activity" was rated third (12\%).

The obtained results show that there is no certain gender domination in the responses of the young men and girls, they have almost equal values according to the choice of reasons interfering with the involvement in the research activity.

\section{Discussion}

The analysis showed the multivalued position of the national scientists regarding the problem of development and support of the woman's scientific capability in Russia. Meanwhile, the percent of involvement of Russian women in science and education gets ahead of the values of many developed countries of the world. The tendency related to the involvement of the Russian women in the scientific and educational activity arisen in the $18^{\text {th }}$ century continued during the whole $19^{\text {th }}$ century and expressed brightly in the $20^{\text {th }}$ century (Soviet period), and was supported in the new time (beginning of the $20^{\text {th }}$ century).

Following the results of the performed theoretical analysis the certain conclusions can be made:

- Possibility of joining the world of science and education by a Russian woman happened much earlier in Russia than in other developed countries of the world and it was more efficient;

- Despite the maintaining of the historical positive tendency a particular "imbalance" is observed in the country in favour of men (minimal number of the Russian women-scientists who joined the higher spheres of the scientific hierarchy);

- The scientific capability of a Russian woman is not realized completely and this requires the creation of the corresponding conditions, development of the socio-cultural mechanisms of its optimization and support. 
Empiric method of research allowed revealing the peculiarities of the organization of the student science in the higher educational institution, its advantages and disadvantages.

The advantages include:

- most of the students in the higher educational institution $(84,8 \%)$ are ready for active participation in the student scientific activity when satisfying all necessary conditions.

- the results of the poll showed the gender unit of the students in the sphere of motivation to the scientific activity.

The disadvantages include:

- low level of motivation of students of both genders to the participation in the scientific activity of the higher educational institution. In terms of amount $(0.8 \%+13.9 \%=14.7 \%)$ estimate their participation in the student science as "quite high" (0.8) and "high" (13.9), and $37.7 \%$ estimate is as "medium", $13.9 \%$ as "low";

- a disturbing indicator characterizing "disengage" or "low level of understanding" of the role of science by the students, one-third of respondents $(31.3 \%)$ could not formulate their attitude to it.

\section{Conclusion}

The results of the research performed allow us to formulate the following conclusions:

1. The woman's scientific capability serves as the most important component of the innovative resource of the country; its optimization has a direct impact on the development of the country, all its social institutions and structures, democratization of the Russian society.

2. The support and development of the woman's scientific capability is connected to the history of the development of our state and society, reflects its best traditions, senses and values of culture.

3. The Russian system of higher vocational education serves the most important factor and condition of formation of the sustainable motivation of students to be engaged in research activity taking into account the gender component.

\section{References}

1. F. Khamdamova, Sci Rev, 10(27), 29-32 (2019). https://doi.org/10.31435/rsglobal_sr/30122019/6865

2. O.A. Valkova, Woman Rus Soc, 1, 89-98 (2018)

3. A.G. Allakhverdyan, Izmeneniya v strukture personala sotsialnykh nauk: gendernyi analiz [Changes in the structure of staff of social sciences: gender analysis], in O.A. Valkova (ed), Materials of the International scientific conference "To the Century anniversary of the Great Russian revolution: women faces of the Russian science inheritance", November 07-08, 2017, Moscow, 372-378. (Publishing House: "Yanua-K", Moscow, 2017)

4. S.M. Vinogradova, Yu.G. Dunaeva, D.F. Ziatdinov, Bul St. Petersburg Univ. Polit Sci. Int Rel, 10(3), 260-268 (2017). https://doi.org/10.21638/11701/spbu06.2017.306

5. E.Z. Mirskaya, E.A. Martynova, Bul RAS, 63(8), 693-700 (1993)

6. I.S. Bogomolova, S.V. Grinenko, E.K. Zadorozhnyaya, Eng Bul Don, 2-2(36), 118 (2015)

7. N.L. Pushkareva, Woman Rus Soc, 3(56), 24-35 (2010) 
8. I. Emelyanovich, Zh. Komarova, Sci Innov, 3, 18-37 (2018)

9. T.K. Rostovskaya, A.M. Egorychev, Man World Cult, 2, 31-38 (2016)

10. I.L. Sizova, N.V. Kladova, T.M. Khusyainov, Woman Rus Soc, 1(78), 60-68 (2016)

11. A.M. Egorychev, A.G. Akhtyan, L.V. Mardakhaev, S.N. Fomina, A.K. Bykov, AD ALTA: J of Interdiscipl Res, 10(2), Spec. Iss. 14, 61-65 (2020)

12. A.M. Mityaeva, S.N. Fomina, N.A. Tsvetkova, A.I. Rybakova, N.S. Gedulyanova, E.A. Khovanskaya, Turkish Online J of Design Art \& Communication, 7, 1-17 (2017)

13. M.W. Rossister, Soc Stud Sci, 23(2), 325-341 (1993)

14. O.S. Rose, What is gender history? (Polity Press, Cambridge, 2010)

15. C. Enloe, Gender Makes the World Go Round, in S. Chan, C. Moore (eds), Theory of International Relations. Vol. IV: Contemporary Reflexive Approaches in International Relations, 89-105 (SAGE Publications Ltd, London; New Delhi, 2006)

16. S.J. Ceci, W.M. Williams, PNAS, 108(4), 3157-3162 (2011)

17. R.E. Nisbett, et al., Amer Psychol, 76(2), 130-159 (2012)

18. N. Hudgins, Hold still, Madame: wartime gender and the photography of women in France during the Great War. (Univ. of St Andrews, 2014)

19. L. Holman, D. Stuart-Fox, C.E. Hauser, PLoS Biol, 16(4), e2004956 (2018). https://doi.org/10.1371/journal.pbio.2004956.

20. K. Cavoukian, N. Shahnazarian, Armenia: Persistent Gender Stereotypes, in S. Franceschet, M.L. Krook, N. Tan (eds), The Palgrave Handbook of Women's Political Rights (2019)

21. E.A. Burdukovskaya, E.V. Rvacheva, Bul Amur State Univ, 42, $72-74$ (2008)

22. Gendernyi sostav nauchnykh kadrov [Gender composition of scientific staff]. Accessed on: October 3, 2021. [Online]. Available: https://issek.hse.ru/news/341451906.html 